\title{
SHRINKAGE OF VARIOUS TYPES OF PORTLAND CLINKER-BASED CEMENTS WITH RESPECT TO THEIR HYDRATION DEGREE
}

\author{
Vendula Davidová, Pavel Reiterman* \\ Czech Technical University in Prague, Faculty of Civil Engineering, Experimental Centre, Thakurova 7, 16629 \\ Prague, Czech Republic \\ * corresponding author: pavel.reiterman@fsv.cvut.cz
}

\begin{abstract}
The volume changes of cement based composites are significantly exhibited in the hardening process. Initial phases of the hardening are complemented by the expansion due to the heat evolution that is subsequently alternated by the shrinkage. Both could cause a crack initiation. It is evident that ultimate volume changes of cement based composites are a complex process, because the final shrinkage is determined by the binder used, exposition and also by the previous history. The paper focuses on the evaluation of the main types of cements based on the Portland clinker by using a conventional procedure for the determination of the shrinkage on the standard cements mortars. These mortars were exposed to drying after 1 and 3 days of curing, related to the actual degree of hydration, which was estimated on the basis of compressive strength development. The hydration process was additionally monitored using thermogravimetry on the accompanying paste specimens during one year. The performed experimental program confirmed the essential sense of the curing regime especially for blended cement systems, which exhibited very low values of the hydration degree at applied curing intervals. Despite the slightly higher values of shrinkage of blended cements, the obtained results signalize the crucial effect of prolonged curing for these types of binders. The conclusion highlighted the necessity of taking into consideration the hydration degree during cement testing by using the conventional contact method. Otherwise, the simple interpretation leads to an overestimation of the less-suitable material solution.
\end{abstract}

KEYWORDs: Drying shrinkage, hydration degree, mechanical properties, Portland cement.

\section{INTRODUCTION}

The cement-based-composites and related products represent a significant part of construction engineering. Their significance is a result of good physical properties and good availability of raw materials. Their suitable mechanical performance together with required durability is commonly the main characteristics taken into account during their application. However, there are other features necessarily solved in engineering practice, which are closely related to their substance; shrinkage is one of them [1-3]. Nevertheless, this aspect causes the initiation of unintended crack propagation resulting in the reduction of the lifespan of the element.

There are a number of reasons leading to volume changes of concrete. Temperature dilatation of concrete structures is usually reflected during the design using valid empirical relations. Volumetric changes induced by varying humidity have a sense for specific applications. However, a sudden loss of moisture, e.g. due to the action of wind or direct sun exposure, during concrete hardening is the reason of so called drying shrinkage [4]. The typical exhibition is shown on Figure 1, where the drying was prevented only on lateral sides due to presence of moulds. This process is important during the construction and the extensive curing serves as a reliable prevention for a long-term durability [5]. However, the ultimate volume changes are closely related to the hydration process for cement based composites and conventional concrete.

Cement hydration is a complex reaction resulting in a solid structure. Its progress is predominantly determined by the composition of the cement used in normal conditions [6]. In addition, the heat evolution is an inherent exhibition of the cement hydration and it is closely related to the cement phase composition. Individual main minerals contained in Portland cement clinker exhibit their specific properties, which are shown in Table 1. An even more detailed explanation was provided by Bullard et al. [7], who described the behaviour of individual clinker materials and their interaction with each other. The volume changes of the cement were thoroughly studied by Paulini [8], who quantified the volume changes for individual clinker minerals, which are shown in Table 1. However, Yodsudjai and Wang [9] reported different values.

Thanks to the detailed description of individual clinker components, the prediction of ultimate volume changes using advanced techniques could be conducted easily [10, 11]. These models take into account the dimensions of the produced element and, on the basis of calculated hydration heat, estimate the resulting 


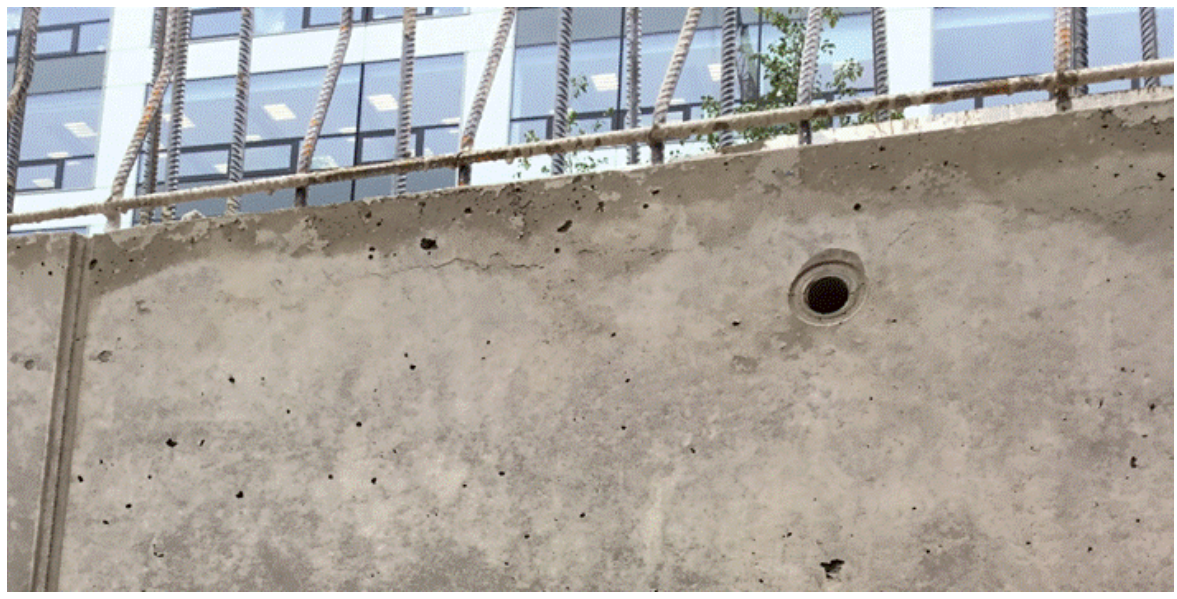

FiguRE 1. Crack originated due to drying of the concrete three days after casting.

\begin{tabular}{|c|c|c|c|c|}
\hline \multicolumn{2}{|c|}{ Clinker minerals } & $\begin{array}{c}\text { Hydration heat } \\
\qquad[\mathrm{kJ} / \mathrm{kg}]\end{array}$ & $\begin{array}{c}\text { Chemical shrinkage } \\
\text { by Paulini }[8] \\
{\left[\mathrm{cm}^{3} / \mathrm{g}\right]}\end{array}$ & $\begin{array}{c}\text { Chemical shrinkage } \\
\text { by Yodsudjai and Wang }[9 \\
{\left[\mathrm{cm}^{3} / \mathrm{g}\right]}\end{array}$ \\
\hline $\mathrm{C}_{3} \mathrm{~S}$ & $3 \mathrm{CaO} \cdot \mathrm{SiO}_{2}$ & 500 & 0.0532 & 0.0704 \\
\hline $\mathrm{C}_{2} \mathrm{~S}$ & $2 \mathrm{CaO} \cdot \mathrm{SiO}_{2}$ & 250 & 0.0400 & 0.0724 \\
\hline $\mathrm{C}_{3} \mathrm{~A}$ & $3 \mathrm{CaO} \cdot \mathrm{Al}_{2} \mathrm{O}_{3}$ & 910 & 0.1113 & 0.115 \\
\hline $\mathrm{C}_{4} \mathrm{AF}$ & $4 \mathrm{CaO} \cdot \mathrm{Al}_{2} \mathrm{O}_{3} \cdot \mathrm{Fe}_{2} \mathrm{O}_{3}$ & 420 & 0.1785 & 0.086 \\
\hline
\end{tabular}

TABle 1. Properties of individual clinker minerals.

stresses. The reduction of cast concrete mass is an efficient approach for the reduction of maximal temperature; in addition, the casted structure is divided into fractional segments and the casting is realized as a "checkerboard". This technology was successfully applied during the erecting of the Hoover Dam or Orlik Dam [12. Active cooling of hardening concrete or precooling of the components prior to the mixing could contribute to the reduction of maximal temperature as well. The abovementioned technologies represent the engineering solutions, however, the most efficient one is the selection of the appropriate binder exhibiting lower hydration heat and lower hydration kinetics. Thus, it is evident that the volume changes of concrete are closely related to the process of hydration.

The reduction of the hydration heat was historically solved by the use of belite cement, however, currently, the application of supplementary cementitious materials (SCM) is preferred [13]. It is partially motivated from the environmental point of view, because these materials come from waste or by-products. They participate in the cement hydration by reacting with $\mathrm{Ca}(\mathrm{OH})_{2}$, which originates during the hydration of $\mathrm{C}_{3} \mathrm{~S}$ and $\mathrm{C}_{2} \mathrm{~S}$. Resulting hydrates, CSH, CAH, CSAH phases, significantly contribute to the density and mechanical properties in time, however, the reaction of the most of SCM is very slow, which significantly reduces the hydration heat but prolongs reaching the standard mechanical performance. The higher reactivity and thus higher reaction kinetics exhibits silica fume due to very high finesses, selected types of metakaolin [14], or fly ash [15 17, which could be treated by an additional grinding [18. The longterm character of the SCM hydration positively limits the chemical shrinkage of cement paste, because their reaction proceeds just in solid environment [19, 20].

The products of a cement hydration exhibit lower molar volume, hence, theoretically, the hydration process should be characterized by the shrinkage 9 . However, hardened cement paste evinces the porosity. Rasoolinejad et al. 21 described that the process of hydration is expansive due to capillary pores in which the water is physically fixed. This hypothesis is valid for humid conditions, respectively in the presence of water, which is necessary for the hydration process. When the concrete is exposed to arid environment, the loss of moisture leads to the drying shrinkage. That means the cement hydration and drying shrinkage are competitive processes, whose importance is very high especially during the hardening.

The main aim of the work performed is an experimental comparison of conventionally used types of Portland cement in terms of shrinkage and the process of hydration. A specific attention was paid to the tendency of studied cements to the drying shrinkage. Cracks induced by the shrinkage significantly reduce the service life of the concrete infrastructure hence it is necessary to characterize related processes in detail for the proposal of the correct approach. 


\begin{tabular}{|c|c|c|c|c|c|c|}
\hline & & CEM I 52.5 & CEM I 42.5 & CEM II/B-S 32.5 & CEM III 32.5 & CEM I 42.5 (SC) \\
\hline $\mathrm{CaO}$ & {$[\%]$} & 63.5 & 61.2 & 50.51 & 44.32 & 63.8 \\
\hline $\mathrm{SiO}_{2}$ & {$[\%]$} & 20.3 & 21.7 & 27.24 & 32.11 & 20.6 \\
\hline $\mathrm{Al}_{2} \mathrm{O}_{3}$ & {$[\%]$} & 4.8 & 5.72 & 7.85 & 7.8 & 4.8 \\
\hline $\mathrm{Fe}_{2} \mathrm{O}_{3}$ & {$[\%]$} & 3.4 & 3.22 & 2.72 & 1.37 & 3.4 \\
\hline $\mathrm{MgO}$ & {$[\%]$} & 1.5 & 2.58 & 3.75 & 6.11 & 1.4 \\
\hline $\mathrm{SO}_{3}$ & {$[\%]$} & 3.1 & 2.94 & 2.85 & 2.99 & 3.2 \\
\hline $\mathrm{K}_{2} \mathrm{O}$ & {$[\%]$} & 0.75 & 0.8 & 0.77 & 0.67 & 0.74 \\
\hline $\mathrm{Na}_{2} \mathrm{O}$ & {$[\%]$} & 0.2 & 0.3 & 0.36 & 0.57 & 0.2 \\
\hline LOI & {$[\%]$} & 1.6 & 1.29 & 1.1 & 0.99 & 1.4 \\
\hline Blaine & {$\left[\mathrm{m}^{2} / \mathrm{kg}\right]$} & 509 & 351 & 345 & 378 & 311 \\
\hline
\end{tabular}

TABLE 2. Chemical composition and selected properties of used cements.

\section{EXPERIMENTAL PROGRAM}

The present experimental program deals with the shrinkage of standard cement based mortars. Five types of conventionally used cements based on Portland clinker were selected; their chemical composition and selected properties are shown in Table 2. Individual cements differ in chemical properties and their mechanical performance as well. (SC) is the abbreviation for road cement in Czech Republic, which exhibits lower content of tricalcium silicate and a lower value of specific surface by Blaine.

Mortars were made from standard siliceous sand according to EN 196-1 [22], mixed with individual cements in proportions $3: 1$; applied water/cement ratio was set to 0.45 for all studied mixtures. Sets of prismatic specimens $20 \times 20 \times 100 \mathrm{~mm}$ were produced for the determination of the shrinkage. After 24 hours, they were demoulded and equipped with the targets, which served for the fixation of the dial test indicator. These procedures were successfully carried out in a previous research [6]. These specimens were divided into three main groups, which differed by the curing regime. A part was left under normal laboratory conditions to induce drying, the rest of the specimens were immersed in the water basin, however, part of the specimens was extracted after 3 days and subsequently kept under normal laboratory conditions as well. Thus, the last set of specimens had a prolonged curing. The mass change was monitored continuously.

The mechanical properties of the studied mixtures were determined in accordance with EN 196-1 [22] using prismatic specimens $40 \times 40 \times 160 \mathrm{~mm}$. Flexural and compressive strength were measured in selected time intervals.

Accompanying specimens of the cement pastes with similar $\mathrm{w} / \mathrm{c}$ were prepared for the thermogravimetric measurement in order to monitor the process of hydration. A themogravimetric analysis was carried out using the DTA-TG apparatus (Schimadzu DTG-60H). The content of chemically bound water $\left(H_{h y d}\right)$, which reflects main constituents contributing to mechanical properties, was determined according to Eq. 1 . where $w_{105}, w_{450}$ mean weight at $105^{\circ} \mathrm{C}, 450^{\circ} \mathrm{C}$ respectively [23, 24].

$$
H_{h y d}=\frac{w_{105}-w_{450}}{w_{105}}
$$

\section{RESUltS AND DISCUSSION}

The performed experimental program focused on the assessment of five types of cements based on the Portland clinker in terms of their shrinkage. A special attention was paid to their predisposition to the drying shrinkage hence the measurement of the shrinkage was conducted for various curing regimes. The results obtained during a one-year measurement period are depicted in Figure 2 the mass loss is shown in Figure 3 The logarithmic scale was applied with respect to the long-term character of the experiment and the progress of monitored values.

The regime of curing had a significant impact on the progress of volume changes, which is obvious in the prolonged curing for up to three days. All mortar specimens with employed cements exhibited slight expansion during the water curing. These results correspond well with conclusions of Rasoolinejad et al. [21], who thoroughly described the causes of the expansion during hydration, which were already mentioned in the introduction. The highest expansion exhibited CEM I 52.5, which attained approximately $0.6 \mathrm{~mm} / \mathrm{m}$ after one year. The lowest expansion was determined on specimens employing the road cement. This fact corresponds with the expectations, because high volume stability is required of such type of the cement. The remaining cements attained very similar results for water curing, which were in the range of $0.42-0.45 \mathrm{~mm} / \mathrm{m}$.

The specimens, exposed to simultaneous drying, exhibited gradual shrinkage after 24 hours. The highest level of shrinkage was reached by CEM III 32.5 with $0.86 \mathrm{~mm} / \mathrm{m}$ after one year. The CEM I 52.5 attained the best final values. The other results were balanced. The prolonged curing brought an expected improvement of the final shrinkage for all studied cements. The correspondence of mass changes with the obtained volume changes is clearly visible in Figure 3 These basic tests are conventionally used for the comparison of various cements, in addition, this procedure serves 

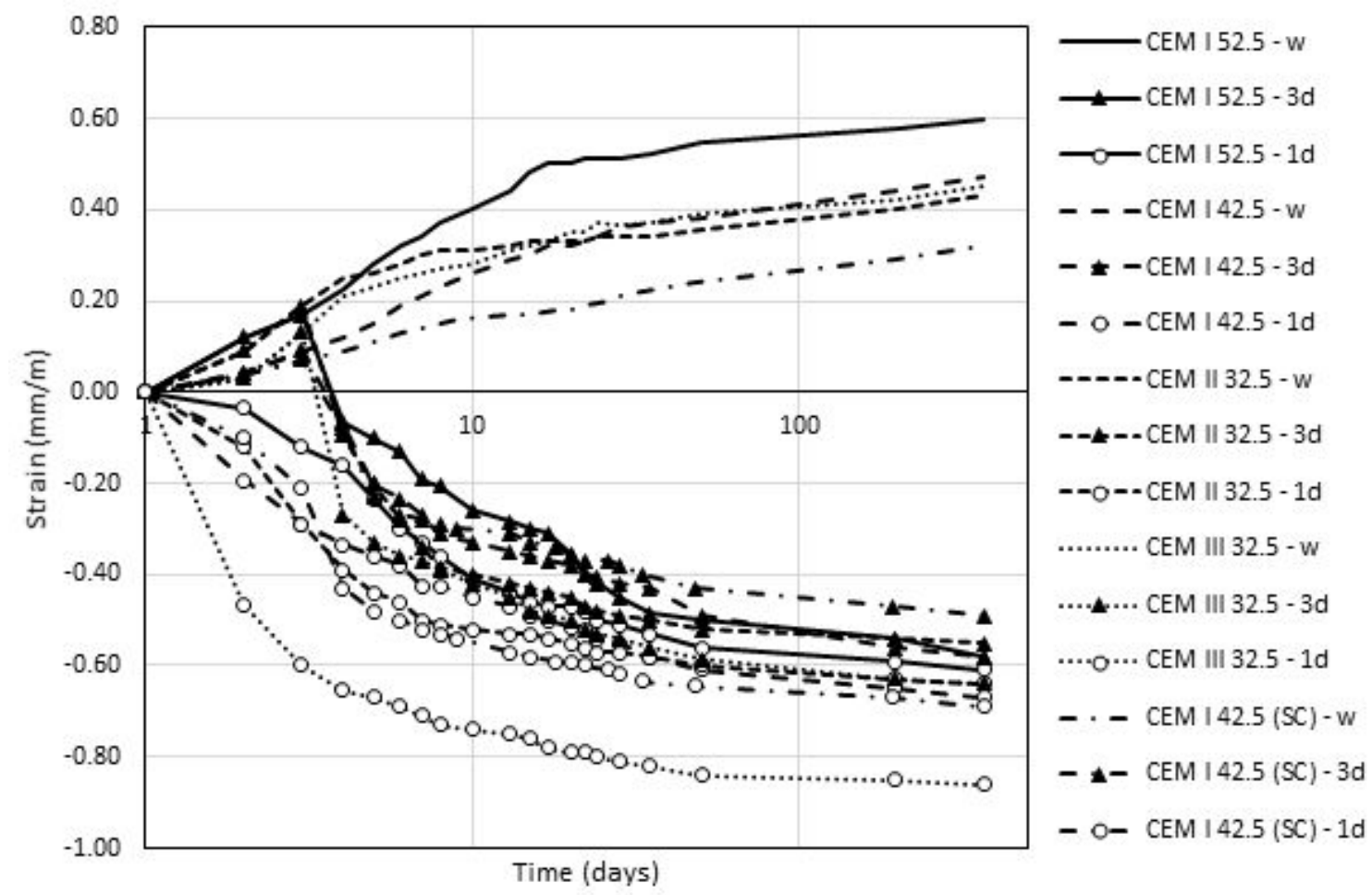

Figure 2. Evolution of strain in time.
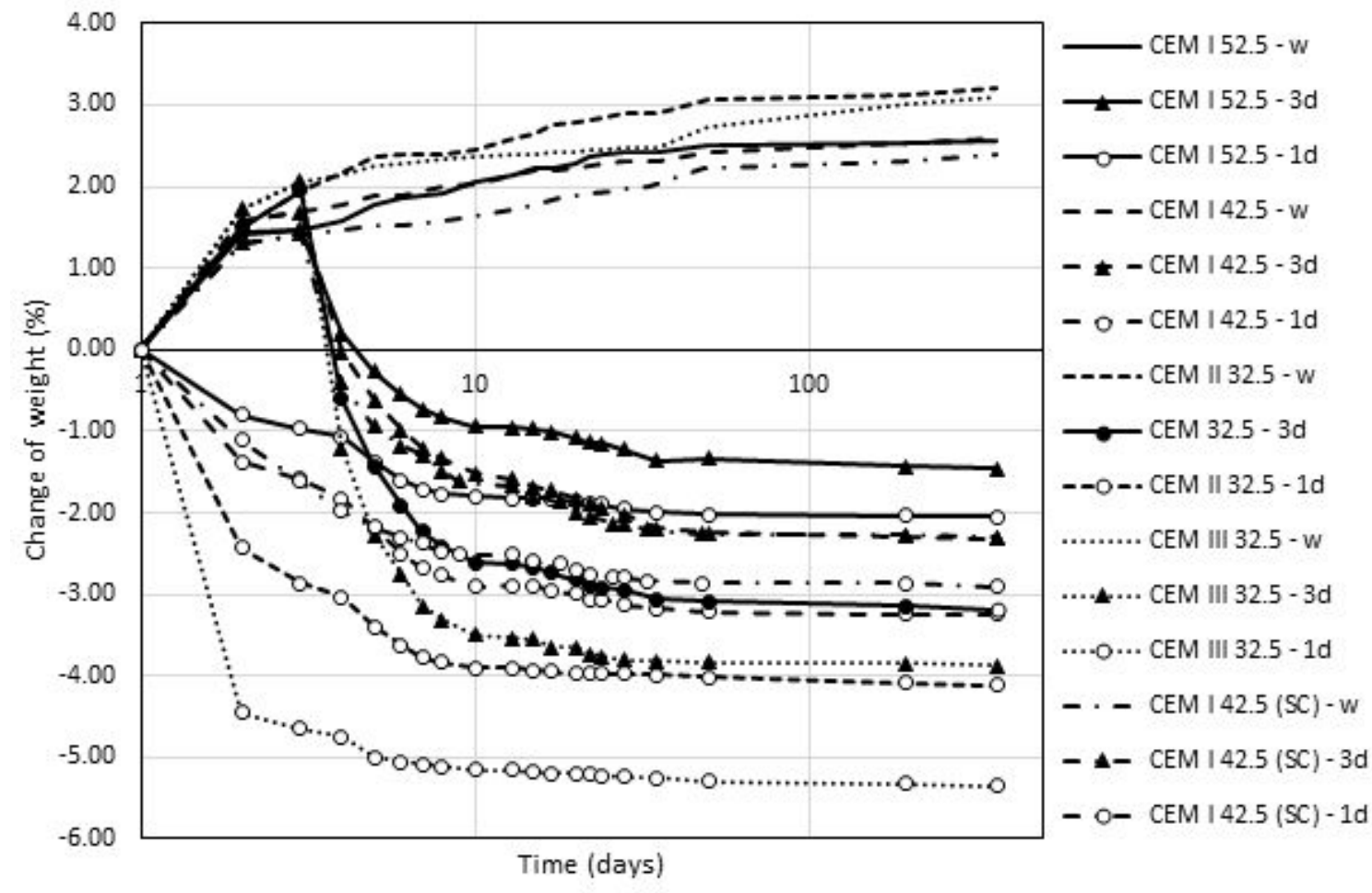

FIGURE 3. Evolution of change of weight in time. 


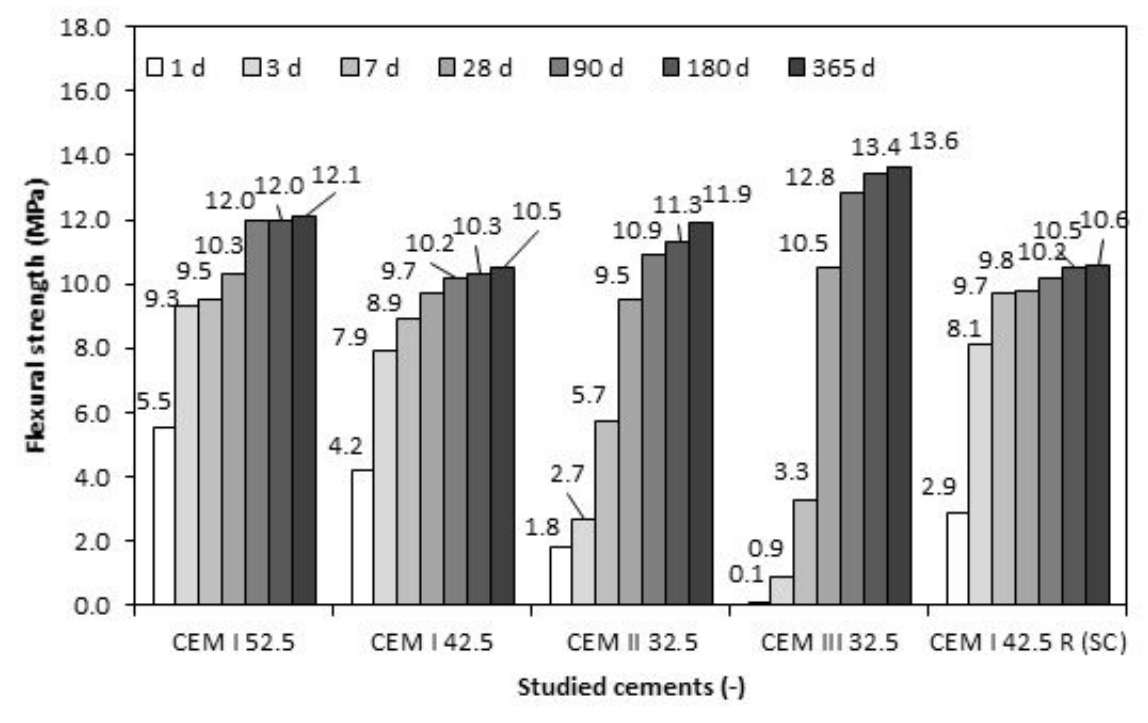

FiguRE 4. Evolution of flexural strength in time.

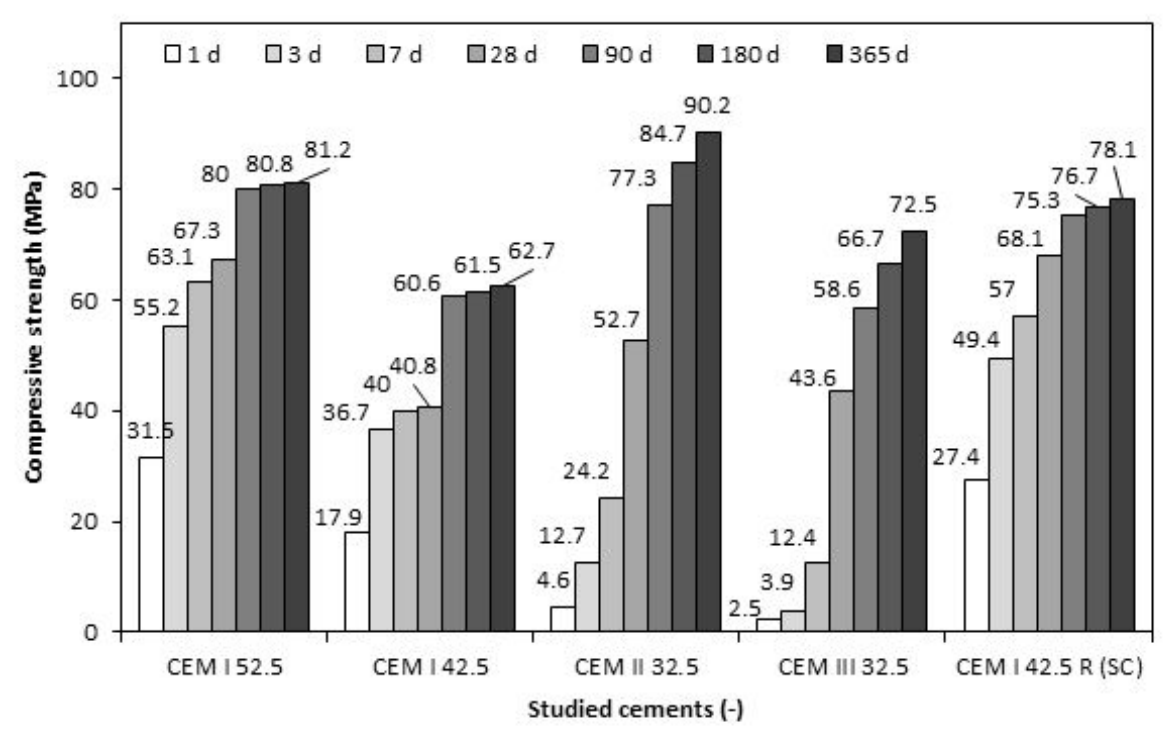

FiguRE 5. Evolution of compressive strength in time.

for the selection of cement for the specific applications. However, it is necessary to assess the obtained results in a broader perspective.

The evolution of mechanical properties of individual cements clearly illustrates the significant differences. The flexural and compressive strength were measured in selected time intervals; the results obtained are depicted in Figure 4 and Figure 5 . The attained mechanical performance fully corresponds with declared strength classes of studied cements, especially for the short-term measurement. Final long-term mechanical properties of CEM II 32.5 are significantly higher due to content of blast furnace slag in comparison with the cements of CEM I, despite lower initial mechanical performance. In addition, a further increase of mechanical properties of CEM III could be expected in time. This factor is crucial for the correct evaluation of the individual cements.

The estimation of the hydration degree could be conducted on the basis of achieved compressive strength. For this purpose, the Michaelis-Menten equation (2) could be successfully applied; this formula is conventionally used for the prediction of chemical processes with an ultimate reaction capacity. It was used in a previous research for the assessment of pozzolanic activity of ceramic powder [25]. Its potential for modelling of the reaction kinetics of cementbased composites was confirmed in other research works [26, 27]. $V_{\max }$ presents the ultimate value of the studied property, $T$ is time, $K$ is constant and $v$ is partial value, usually measured points; compressive 


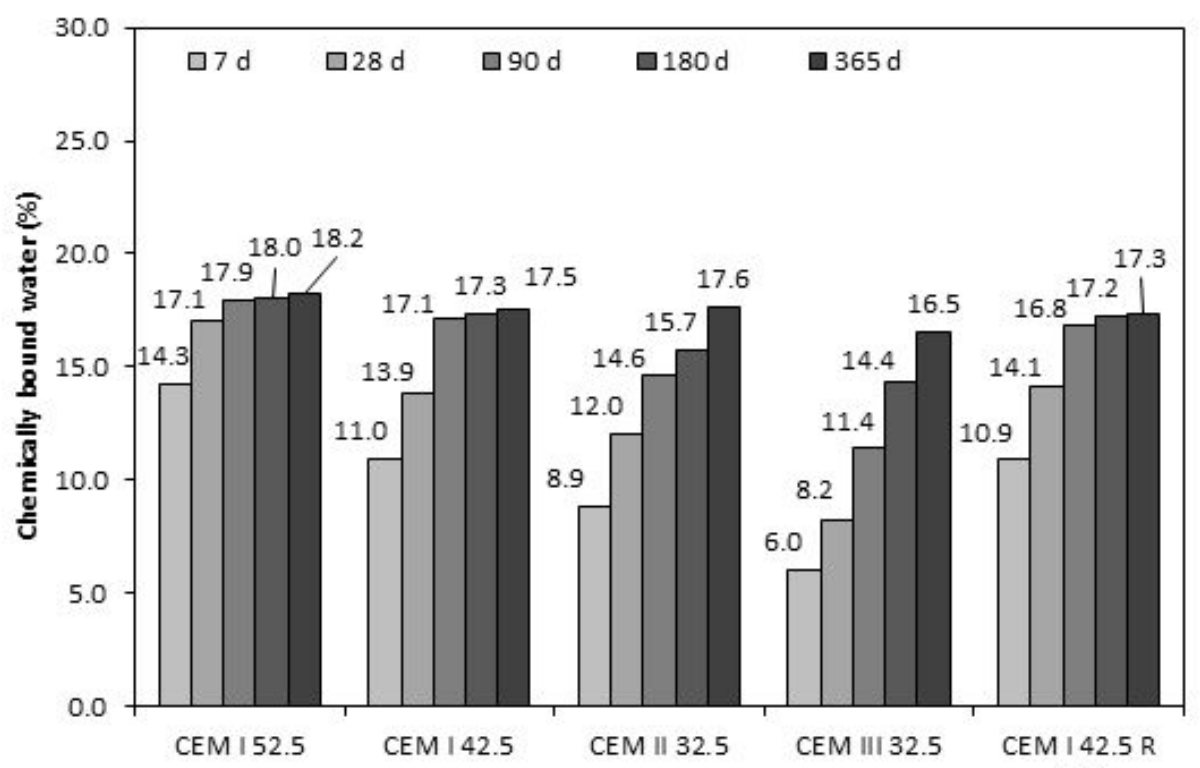

(SC)

Studied cements (-)

Figure 6. Chemically bound water in time in cement pastes.

strength or chemically bound water in relevant time in our case.

$$
v=V_{\max } \frac{T}{K+T}
$$

Chemically bound water in cement pastes is a suitable indicator of the hydration process of cement based composites, especially the development of mechanical properties. Achieved values of chemically bound water in accompanied paste specimens are illustrated in Figure 6. Results obtained from the thermogravimetric measurement indicated crucial differences in hydration kinetics of individual cements as well. It can be concluded that the obtained kinetics correspond well with the results of the compressive strength. The relationship between compressive strength and obtained values of chemically bound water is illustrated in Figure 7. The correspondence is well visible on the estimated values of hydration degree on the basis of compressive strength and chemically bound water, respectively, which are illustrated in Figure 8 and Figure 9

The estimation obtained on the basis of compressive strength is illustrated in Figure 7 , where the significant differences in individual cements are clearly visible. The estimation on the basis of the thermogravimetric measurement is shown in Figure 8 this estimation was negatively affected by the missing values of early measurement, however, it offers a suitable fit with the results achieved on the basis of compressive strength evolution. The values of CEM I 42.5 and CEM I 42.5 (SC) overlap, which indicates their high similarity. On the one hand, the determination of the hydration degree is a complicated issue, especially in the case of blended cement-based binders [26] 28], on the other hand, the evolution of compressive strength offers a good fit [26, 28].

With respect to the achieved resolution of both used approaches of the hydration degree estimation, the values on the basis of compressive strength were used for the following evaluation and conclusions. The values of the hydration degree after one and three days are shown in Table 3 in order to evaluate the regimes of curing in terms of the shrinkage. The various reaction kinetics of the employed cement is evident. After one day, the cements of class I exhibited the hydration degree of approximately $30 \%$, whereas the cements containing a considerable amount of the mineral additive exhibited just about $4.0 \%$; a 7.5 times lower value. After three days, the hydration degree of blended cements was almost three times higher, in the case of CEM I cements, two times higher, however they underwent the dominant part of the hydration. Although the estimation of the ultimate values for blended systems is problematic, for the problem studied, it offers a satisfactory perspective.

Drying shrinkage is a complicated phenomenon, because it is affected by a number of various factors. However, the diffusion of moisture is the major one in the case of hardening concrete. This fact was confirmed by Vinkler and Vítek 4 in a thorough study, who investigated the shrinkage of conventional concrete under various conditions. They compared the results of real scale tests with the standard laboratory specimens, which exhibited approximately two times higher shrinkage. Moreover, in the case of a real scale measurement, the shrinkage was reduced proportionally with an increasing thickness of the segment. Accompanying specimens, kept under normal laboratory conditions, attained a higher shrinkage than 


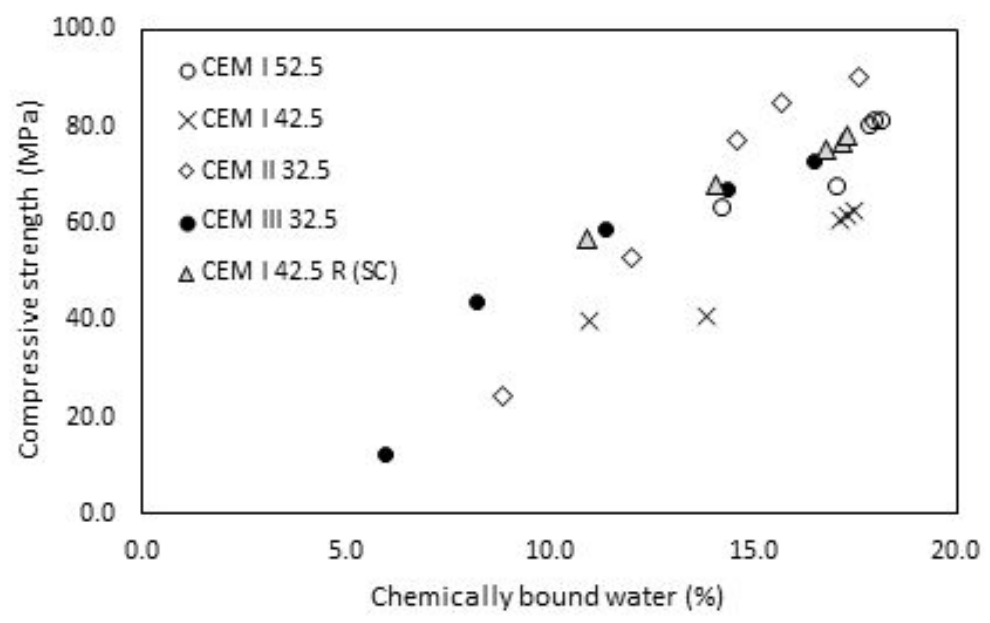

FigURE 7. Relationship between compressive strength and obtained values of chemically bound water.

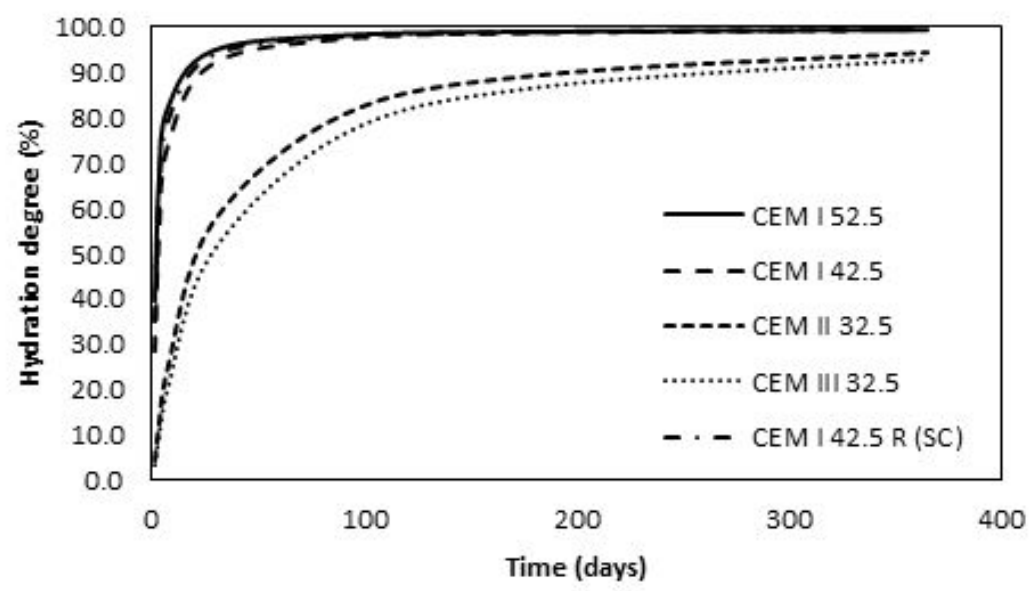

FIGURE 8. Estimated hydration degree on the basis of the compressive strength evolution.

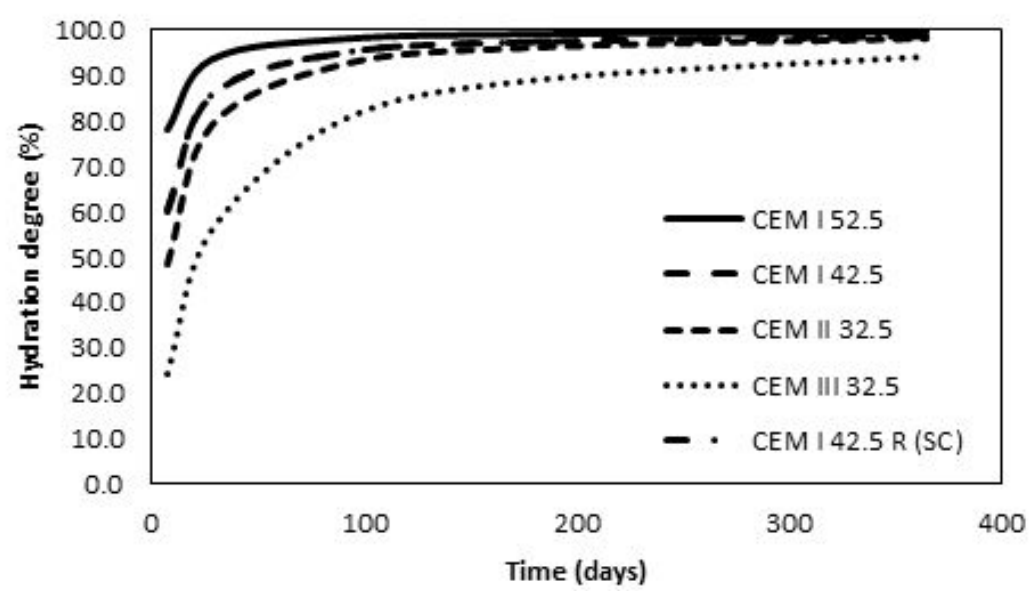

Figure 9. Estimated hydration degree on the basis of the chemically bound water. 


\begin{tabular}{lrr}
\hline & \multicolumn{2}{c}{ Degree of hydration [\%] } \\
& $1 \mathrm{~d}$ & $3 \mathrm{~d}$ \\
\hline CEM I 52.5 & 39.9 & 66.5 \\
CEM I 42.5 & 28.4 & 54.4 \\
CEM II 32.5 & 4.5 & 12.3 \\
CEM III 32.5 & 3.5 & 9.8 \\
CEM I 42.5 (SC) & 35.0 & 61.8 \\
\hline
\end{tabular}

TABLE 3. Estimated degree of hydration for studied cements in selected ages.

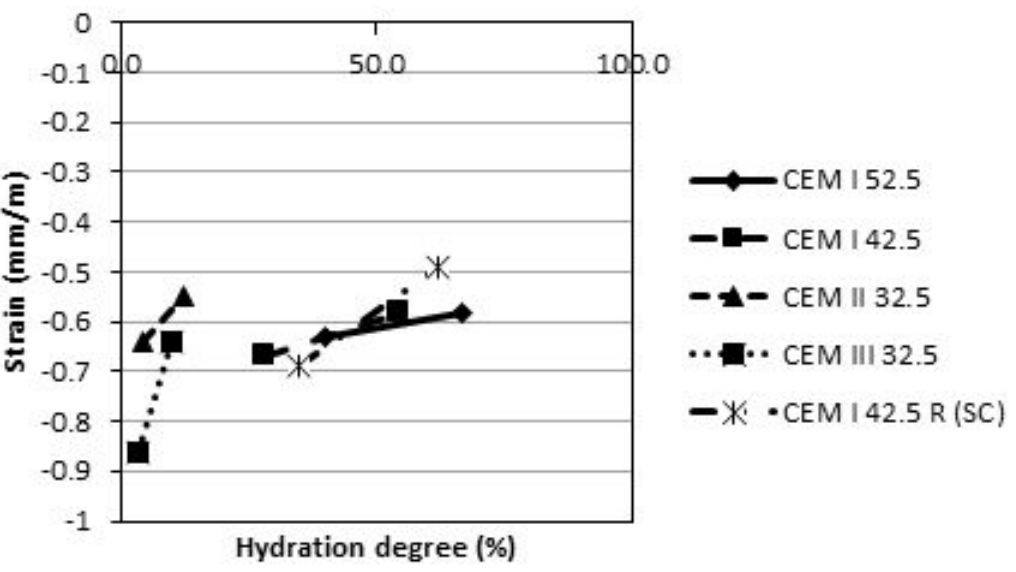

FiguRe 10. Rate of drying shrinkage with respect to the hydration degree at the end of the curing.

those stored in moist environment by $10 \%$. The diffusion properties of concrete are considerably dependent on the actual content of moisture in case of the hardened concrete, however, the moisture is not tightly fixed by capillary forces in early age concrete, because of the progressing hydration. And thus, in such concrete, the moisture is lost rapidly, which interrupts the successful hardening process. These conclusions were reported by Holt and Leivo [1], who monitored capillary forces and evaporation of the moisture of various concrete mixtures. That clearly evinces the direct dependence of the hydration degree with the sensitivity to drying shrinkage, which could be illustrated on the basis of the results obtained, Figure 10 The reached shrinkage of individual cements and given hydration degree is shown, when the specimens were induced to the drying. The low hydration degree of blended cements led to a sudden loss of moisture and subsequent huge drying shrinkage when exposed to drying after 24 hours. However, the prolonged curing, up to three days, caused a significant improvement of final shrinkage, whereas for CEM I cements, the reduction of shrinkage was negligible. These findings amplified the necessity of curing in the case of blended cements, and moreover, highlighted the nature of the methodology used. This contact method is conventionally used for the selection of suitable cement, nevertheless, the detailed view declares that different factors are measured for single binder systems. The used type of measurement could cover a part of autogenous shrinkage of blended cements due to their lower hydration kinetics, whereas higher initial kinetics causes considerable result distortion because of the absence of autogenous shrinkage and lower permeability. Predominantly, the absence of the autogenous shrinkage factor could lead to the underestimation of cements with an increased reactivity. That could be shown by the thorough research by Yodsudjai and Wang 9 , who determined the chemical shrinkage of various cements. It was reported that, after 24 hours, the CEM I attained approximately $50 \%$ of the 28-day shrinkage.

Autogenous shrinkage plays an important role in the concrete industry, because it starts after the concrete is casted and cannot be avoided by a construction practice [1, 29, 30]. Moreover, its measurement is very complicated through conventional methods, which was well declared by the conducted program. With respect to the nature of this process, the prevention has to be based on the proper mix design and especially the choice of the binder. Primarily, the autogenous shrinkage is reduced by fly ash or blast furnace slag application and by the increase of $\mathrm{w} / \mathrm{c}$ [31. The abovementioned recommendations were complemented by Yodsudjai and Wang [9], who reported a negative impact of the increased amount of C3A, C4AF and increased content of alkalis. Hence, the problem of autogenous shrinkage became of global importance due to the massive development of high-performance concrete mixtures [2]. In addition, it is necessary to interpret the results obtained relative to the attained degree of hydration, because binders with higher re- 


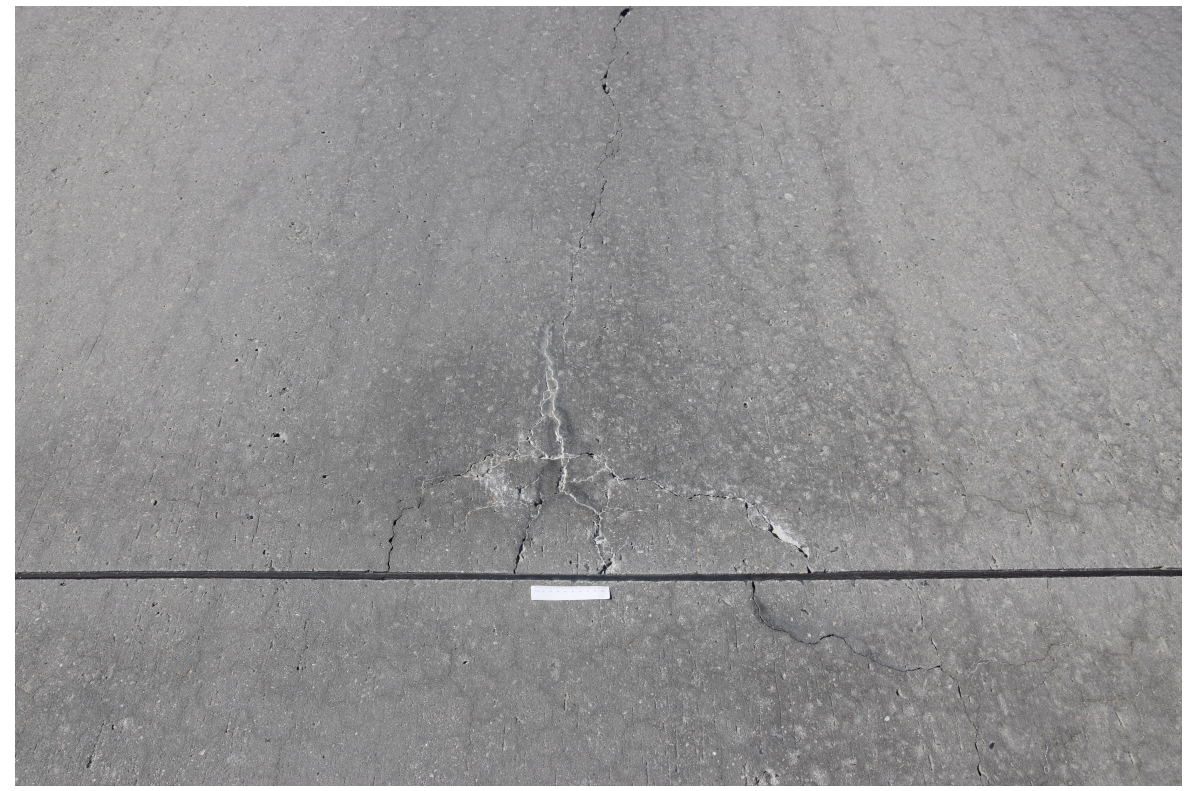

FiguRE 11. Accelerated damage of concrete highway (D5 9-20 km) determined by cracks induced by the shrinkage.

action kinetics are significantly overestimated. Often invisible micro-crack initiation is strongly propagated during the service of the given concrete structure, which results in massive deterioration, as is illustrated on Figure 11.

\section{Conclusion}

The conducted experimental program was focused on the monitoring of the properties of conventionally used types of cements in terms of their shrinkage determined by a conventional contact method. Various curing regimes were applied. These results were analysed relative to the actual mechanical performance and the degree of hydration, which was estimated on the basis of a thermal analysis. The main outcomes of the performed program could be summarized as follows:

- Reaction kinetics of the cements essentially determines the character of the measurement by using a conventional contact method,

- Prolonged curing reduces final shrinkage,

- Higher kinetics of cement hydration suppress the effect of the autogenous shrinkage and led to the significant overestimation of studied cements,

- Lower kinetics of cement hydration led to the dominance of the drying shrinkage and a significant misrepresentation of obtained results, because the drying shrinkage is controlled by the diffusion,

- The comparison of various cements has to be carried out relatively to the actual degree of hydration.

\section{ACKNOWLEDGEMENTS}

This work was supported by the Czech Science Foundation under project No. 19-11027S.

\section{REFERENCES}

[1] E. Holt, M. Leivo. Cracking risks associated with early age shrinkage. Cement and Concrete Composites 26(5):521 - 530, 2004 DOI:10.1016/S0958-9465(03)00068-4

[2] P.-C. Aitcin. Cements of yesterday and today: Concrete of tomorrow. Cement and Concrete Research 30(9):1349 - 1359, 2000. DOI:10.1016/S0008-8846(00)00365-3

[3] A. Zemanová, R. Sovják, J. Litos. Restrained shrinkage test of high performance concrete ring specimen. In Mechanical, Thermal and Hygric Properties of Buildings Materials, vol. 982 of Advanced Materials Research, pp. 38 - 43. Trans Tech Publications Ltd, 2014. DOI:10.4028/www.scientific.net/AMR.982.38

[4] M. Vinkler, J. Vítek. Drying and shrinkage of massive concrete wall segments - 3 years experiment and analytical observations. Materials and Structures 52, 2019. DOI:10.1617/s11527-019-1329-x.

[5] M. Glinicki, R. Jaskulski, M. Dąbrowski. Design principles and testing of internal frost resistance of concrete for road structures - critical review. Roads and Bridges - Drogi i Mosty 15:21 - 43, 2016. DOI:10.7409/rabdim.016.002

[6] V. Davidová, P. Reiterman. Autogenous shrinkage of composites based on portland cement. Acta Polytechnica CTU Proceedings 22:22 - 25, 2019. DOI:10.14311/APP.2019.22.0022.

[7] J. W. Bullard, H. M. Jennings, R. A. Livingston, et al. Mechanisms of cement hydration. Cement and Concrete Research 41(12):1208 - 1223, 2011. DOI:10.1016/j.cemconres.2010.09.011.

[8] P. Paulini. A through solution model for volume changes of cement hydration. Cement and Concrete Research 24(3):488 - 496, 1994. DOI:10.1016/0008-8846(94)90137-6

[9] W. Yodsudjai, K. Wang. Chemical shrinkage behavior of pastes made with different types of cements. 
Construction and Building Materials 40:854 - 862, 2013. DOI:10.1016/j.conbuildmat.2012.11.053

[10] J. Mádlová, P. Štemberk, A. Kohoutkova. Finite element simulation of hydration heat using fuzzy logic model of hydration. In Special Concrete and Composites 2015, vol. 677 of Key Engineering Materials, pp. 157 162. Trans Tech Publications Ltd, 2016. DOI:10.4028/www.scientific.net/KEM.677.157.

[11] Z. P. Bažant, S. Baweja. Creep and shrinkage prediction model for analysis and design of concrete structures - model b3. Materials and Structures 28:357 - 365, 1995. DOI:10.1007/bf02473152.

[12] O. Zobal., P. Padevet, V. Šmilauer, et al. Experimental analysis of mechanical and material properties of concrete orlik dam after 50 years. In Proceedings of 30th Danubia-Adria Symposium on Advances in Experimental Mechanics, DAS 2013 Proceedings 2013, pp. 189 - 190. Primosten, 2013.

[13] P. Van den Heede, J. Furniere, N. De Belie. Influence of air entraining agents on deicing salt scaling resistance and transport properties of high-volume fly ash concrete. Cement and Concrete Composites 37:293 303, 2013. DOI:10.1016/j.cemconcomp.2013.01.005

[14] P. J. Gleize, M. Cyr, G. Escadeillas. Effects of metakaolin on autogenous shrinkage of cement pastes. Cement and Concrete Composites 29(2):80 - 87, 2007. DOI:10.1016/j.cemconcomp.2006.09.005

[15] M. Nili, A. Ehsani. Investigating the effect of the cement paste and transition zone on strength development of concrete containing nanosilica and silica fume. Materials \& Design 75:174 - 183, 2015. DOI:10.1016/j.matdes.2015.03.024

[16] P. Suraneni, A. Hajibabaee, S. Ramanathan, et al. New insights from reactivity testing of supplementary cementitious materials. Cement and Concrete Composites 103:331 - 338, 2019. DOI:10.1016/j.cemconcomp.2019.05.017

[17] B. Lothenbach, K. Scrivener, R. Hooton. Supplementary cementitious materials. Cement and Concrete Research 41(12):1244 - 1256, 2011. DOI:10.1016/j.cemconres.2010.12.001.

[18] K. Dvořák, D. Dolák, D. Paloušek, et al. The effect of the wear of rotor pins on grinding efficiency in a high-speed disintegrator. Materials Science 24, 2018. DOI:10.5755/j01.ms.24.1.17737.

[19] M. Megat Johari, J. Brooks, S. Kabir, P. Rivard. Influence of supplementary cementitious materials on engineering properties of high strength concrete. Construction and Building Materials 25(5):2639 - 2648, 2011. DOI:10.1016/j.conbuildmat.2010.12.013

[20] P. Havlásek, V. Šmilauer, K. Hájková, L. Baquerizo. Thermo-mechanical simulations of early-age concrete cracking with durability predictions. IOP Conference Series: Materials Science and Engineering 236:012052, 2017. DOI:10.1088/1757-899x/236/1/012052.
[21] M. Rasoolinejad, S. Rahimi-Aghdam, Z. Bazant. Prediction of autogenous shrinkage in concrete from material composition or strength calibrated by a large database, as update to model b4. Materials and Structures 52, 2019. DOI:10.1617/s11527-019-1331-3

[22] EN 196-1 - Methods of testing cement - Part 1: Determination of strength. Standard, European Committee for Standardization (CEN), 2005.

[23] K. De Weerdt, K. Kjellsen, E. Sellevold, H. Justnes. Synergy between fly ash and limestone powder in ternary cements. Cement and Concrete Composites 33(1):30 38, 2011. DOI:10.1016/j.cemconcomp.2010.09.006

[24] P. Reiterman, O. Holcapek, O. Zobal, M. Keppert. Freeze-thaw resistance of cement screed with various supplementary cementitious materials. Reviews on advanced materials science 58:66 - 74, 2019. DOI:10.1515/rams-2019-0006

[25] P. Reiterman, M. Keppert. Effect of ceramic powder particle size distribution on its reactivity in lime-based binders. In Binders, Materials and Technologies in Modern Construction III, vol. 908 of Materials Science Forum, pp. 40 - 44. Trans Tech Publications Ltd, 2017. DOI:10.4028/www.scientific.net/MSF.908.40

[26] S. Monteagudo, A. Moragues, J. Gálvez, et al. The degree of hydration assessment of blended cement pastes by differential thermal and thermogravimetric analysis. morphological evolution of the solid phases. Thermochimica Acta 592:37 - 51, 2014. DOI:10.1016/j.tca.2014.08.008

[27] W. Deboucha, N. Leklou, A. Khelidj, M. N. Oudjit. Hydration development of mineral additives blended cement using thermogravimetric analysis (tga): Methodology of calculating the degree of hydration. Construction and Building Materials 146:687 - 701, 2017. DOI:10.1016/j.conbuildmat.2017.04.132

[28] P. Reiterman, O. Holčapek, V. Davidová, et al. Estimation of hydration degree of blended cements with the help of k-values. Materials 12:2420, 2019. DOI:10.3390/ma12152420.

[29] C. Jiang, Y. Yang, Y. Wang, et al. Autogenous shrinkage of high performance concrete containing mineral admixtures under different curing temperatures. Construction and Building Materials 61:260 - 269, 2014. DOI:10.1016/j.conbuildmat.2014.03.023.

[30] J. Liu, K. Yan, X. Zhao, Y. Hu. Prediction of autogenous shrinkage of concretes by support vector machine. International Journal of Pavement Research and Technology 9(3):169 - 177, 2016. DOI:10.1016/j.ijprt.2016.06.003

[31] X. Hu, C. Shi, Z. Shi, et al. Early age shrinkage and heat of hydration of cement-fly ash-slag ternary blends. Construction and Building Materials 153:857 - 865, 2017. DOI:10.1016/j.conbuildmat.2017.07.138 